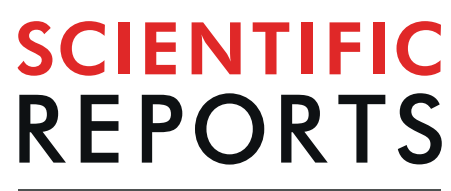

natureresearch

Check for updates

\title{
A non-anhydrous, minimally basic protocol for the simplification of nucleophilic ${ }^{18} \mathrm{~F}$-fluorination chemistry
}

\begin{abstract}
J. A. H. Inkster ${ }^{1,2}$, V. Akurathi ${ }^{1,2}$, A. W. Sromek ${ }^{2,3}$, Y. Chen ${ }^{2,3}$, J. L. Neumeyer ${ }^{2,3}$ \& A. B. Packard ${ }^{1,2 区}$
Fluorine-18 radiolabeling typically includes several conserved steps including elution of the $\left[{ }^{18} \mathrm{~F}\right]$ fluoride from an anion exchange cartridge with a basic solution of $\mathrm{K}_{2} \mathrm{CO}_{3}$ or $\mathrm{KHCO}_{3}$ and Kryptofix 2.2.2. in mixture of acetonitrile and water followed by rigorous azeotropic drying to remove the water. In this work we describe an alternative "non-anhydrous, minimally basic" ("NAMB") technique that simplifies the process and avoids the basic conditions that can sometimes limit the scope and efficiency of $\left[{ }^{18} \mathrm{~F}\right]$ fluoride incorporation chemistry. In this approach, $\left[{ }^{18} \mathrm{~F}\right] \mathrm{F}^{-}$is eluted from small (10-12 mg) anionexchange cartridges with solutions of tetraethylammonium bicarbonate, perchlorate or tosylate in polar aprotic solvents containing $10-50 \%$ water. After dilution with additional aprotic solvent, these solutions are used directly in nucleophilic aromatic and aliphatic ${ }^{18} \mathrm{~F}$-fluorination reactions, obviating the need for azeotropic drying. Perchlorate and tosylate are minimally basic anions that are nevertheless suitable for removal of $\left[{ }^{18} \mathrm{~F}\right] \mathrm{F}^{-}$from the anion-exchange cartridge. As proof-of-principle, "NAMB" chemistry was utilized for the synthesis of the dopamine $D_{2} / D_{3}$ antagonist $\left[{ }^{18} \mathrm{~F}\right]$ fallypride.
\end{abstract}

The production of ${ }^{18} \mathrm{~F}$-labeled compounds for Positron Emission Tomography (PET) typically follows a set of conserved steps for the preparation of reactive $\left[{ }^{18} \mathrm{~F}\right] \mathrm{F}^{-}$(Fig. 1a). The cyclotron-produced $\left[{ }^{18} \mathrm{~F}\right] \mathrm{F}^{-}$is extracted from the $\left[{ }^{18} \mathrm{O}_{\mathrm{H}_{2}} \mathrm{O}\right.$ target using a quaternary methylammonium (QMA) or macroporous QMA (MP-1) anion-exchange (AEX) resin ${ }^{1}$. The $\left[{ }^{18} \mathrm{~F}\right] \mathrm{F}^{-}$is then eluted from the resin using an $\mathrm{MeCN}$-water solution of $\mathrm{K}_{2} \mathrm{CO}_{3}$ or $\mathrm{KHCO}_{3}$ and Kryptofix 2.2.2. $\left(\mathrm{K}_{2.2 .2}\right)$, with the $\mathrm{CO}_{3}{ }^{2-}$ or $\mathrm{HCO}_{3}{ }^{-}$anion displacing the $\left[{ }^{18} \mathrm{~F}\right] \mathrm{F}^{-}$from the AEX resin and $\mathrm{K}_{2.2 .2}$ acting as a phase-transfer catalyst (PTC) in the subsequent ${ }^{18} \mathrm{~F}$-fluorination reaction ${ }^{2}$. Alternative eluents include tetrabutylammonium bicarbonate $(\mathrm{TBAB})$ and tetraethylammonium bicarbonate (TEAB), in which the tetra-butylammonium cation serves as a PTC. The water is then removed from the eluate by azeotropic distillations in which successive portions of acetonitrile are added to the vial and then removed by heating under a stream of inert gas. This "drydown" process is considered crucial to the success of ${ }^{18} \mathrm{~F}$ radiolabeling because hydrated fluoride is generally thought to be poorly nucleophilic ${ }^{3}$. After the $\left[{ }^{18} \mathrm{~F}\right] \mathrm{F}^{-}$has been dried, a solution of the precursor compound in an anhydrous solvent is added to the dried $\left[{ }^{18} \mathrm{~F}\right] \mathrm{F}^{-}$, and the reaction mixture is heated to produce the desired product.

This technique is reliable and extraction of $\left[{ }^{18} \mathrm{~F}\right] \mathrm{F}^{-}$from the AEX cartridges is typically very high. There are, however, limitations to this approach. These include: 1 . the fact that many precursor compounds and ${ }^{18} \mathrm{~F}$ tracers do not tolerate basic reaction conditions very well, especially at high temperatures; 2 . small variations in the drydown step are often cited as a factor in the batch-to-batch differences in yield observed during the production of ${ }^{18} \mathrm{~F}$ radiopharmaceuticals for clinical use; and 3. some $\left[{ }^{18} \mathrm{~F}\right] \mathrm{F}^{-}$is always lost due to volatilization and adsorption of the dried $\mathrm{K}\left[{ }^{18} \mathrm{~F}\right] \mathrm{F}$ onto the walls of the reaction vessel during the drydown process. Eliminating these limitations could improve the reliability of ${ }^{18} \mathrm{~F}$ radiopharmaceutical production.

There have, therefore, been multiple efforts to improve this process. These have included: (1) The use of alternative AEX sorbents, including an $N$-vinyl lactam/divinylbenzene copolymer preloaded with long-chain quaternary ammonium salts ${ }^{4}$ and $\mathrm{C}_{18}$ cartridges impregnated with a phosphonium borane ${ }^{5}$; (2) The use of elution matrices containing strong organic bases (e.g., phosphazenes ${ }^{6}$ and pyridines ${ }^{7}$ ), inert salts (e.g. potassium

${ }^{1}$ Division of Nuclear Medicine and Molecular Imaging, Boston Children's Hospital, Boston, MA, 02115, USA. ${ }^{2}$ Harvard Medical School, Boston, MA, 02115, USA. ${ }^{3}$ Division of Basic Neuroscience, McLean Hospital, Belmont, MA, 02478, USA. ${ }^{凶}$ email: alan.packard@childrens.harvard.edu 


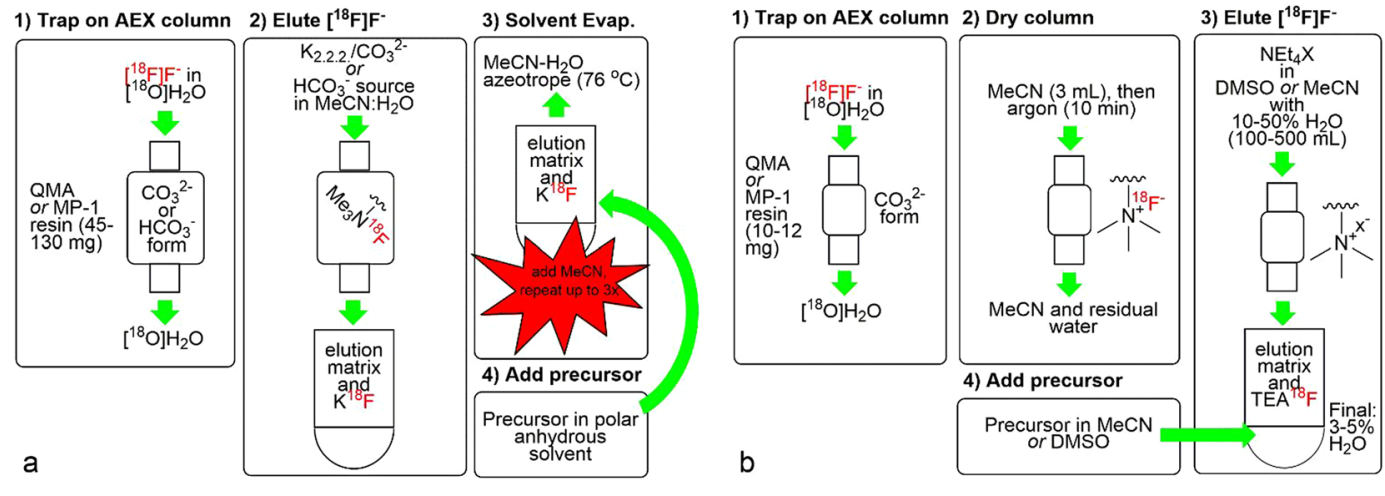

Figure 1. Traditional (a) and "non-anhydrous, minimally-basic" NAMB (b) approaches to the extraction, preparation and use of $\left[{ }^{18} \mathrm{~F}\right] \mathrm{F}^{-}$for the manufacture of PET radiopharmaceuticals. $\mathrm{X}^{-}=\mathrm{HCO}_{3}{ }^{-}, \mathrm{ClO}_{4}^{-}$, or OTs ${ }^{-}$.

mesylate $^{8}$, $\left.[\mathrm{bmim}][\mathrm{OTf}]^{9}\right)$, or anhydrous solutions of $\left[\mathrm{K}_{2.2 .2}\right] \mathrm{OH}^{10}$; and (3) The use of a $\mathrm{TiO}_{2}$ catalyst to carry out ${ }^{18} \mathrm{~F}$-fluorinations without isolating the $\left[{ }^{18} \mathrm{~F}\right] \mathrm{F}^{-}$from the target $\left[{ }^{18} \mathrm{O}\right] \mathrm{H}_{2} \mathrm{O}^{11}$. Other examples include the work of Richarz, et al. who described a "minimalist" approach in which $\left[{ }^{18} \mathrm{~F}\right] \mathrm{F}^{-}$is eluted from QMA cartridges using $\mathrm{MeOH}$ or EtOH solutions where the cation is the trimethylanilinium, diaryliodonium, or triarylsulfonium derivative of the aromatic target compound and the anion is $\mathrm{TfO}^{-}$or $\mathrm{Br}^{-12}$. The cation serves as the $\mathrm{PTC}$ and the $\mathrm{TfO}^{-}$ or $\mathrm{Br}^{-}$counterion displaces the $\left[{ }^{18} \mathrm{~F}\right] \mathrm{F}^{-}$from the AEX resin. However, the eluting solvent must still be removed by distillation and replaced with a polar aprotic reaction solvent. Neumann, et al. described a related approach in which $\left[{ }^{18} \mathrm{~F}^{-} \mathrm{F}^{-}\right.$is eluted from the AEX cartridge using uronium salt-based precursors in 10:1 2-butanone:EtOH, and the ${ }^{18} \mathrm{~F}$-labeling reaction is carried out after addition of tributylamine to the eluate ${ }^{13}$. While not a general approach to $\left[{ }^{18} \mathrm{~F}\right] \mathrm{F}^{-}$incorporation, this approach permits the incorporation of $\left[{ }^{18} \mathrm{~F}\right] \mathrm{F}^{-}$into electron-rich (i.e. unactivated) aryl rings, and thus stands to make a significant impact in this research area. Another example of an innovative way to avoid the drydown step is the work of Basuli, et al. who discovered that certain ${ }^{18} \mathrm{~F}$-fluorination reactions will take place on the surface of a QMA resin at room temperature. Using this method, they prepared the prosthetic group $\left[{ }^{18} \mathrm{~F}\right]$ fluoronicotinic acid-2,3,5,6-tetrafluorophenyl ester by passing the trimethylammonium triflate precursor through an AEX cartridge impregnated with $\left[{ }^{18} \mathrm{~F}\right] \mathrm{F}^{-14}$. The ${ }^{18} \mathrm{~F}$-labeled product was then immediately added to solutions containing amine-bearing targeting vectors [e.g.c (RGDfK), albumin, and a prostate-specific membrane antigen (PSMA) inhibitor $]$ to produce the $\left[{ }^{18} \mathrm{~F}\right]$ fluoronicotinic amides ${ }^{15}$.

The simplest approach to avoiding the drydown step is to use the $\left[{ }^{18} \mathrm{~F}\right] \mathrm{F}^{-}$eluted from AEX cartridges directly, without azeotropic drying. In one example of this approach, Brichard and Aigbirhio ${ }^{16}$ used high concentrations of TEAB $(15 \mathrm{mg} / \mathrm{mL})$ in large elution volumes $(1 \mathrm{~mL})$ to elute $\left[{ }^{18} \mathrm{~F}^{-} \mathrm{F}^{-}\right.$from $130 \mathrm{mg} \mathrm{Sep}-\mathrm{Pak}{ }^{\circledR} \mathrm{QMA}$ cartridges. The decay corrected (DC) elution efficiencies using these "damp" solutions of MeCN or DMF were 95-99\% and $88-99 \%$, respectively. When using DMSO, 5\% water was required in order to achieve an elution efficiency of $89 \%$. Subsequently, $100 \mu \mathrm{L}$ fractions of the eluate, each containing $7.8 \mu \mathrm{mol}(1.5 \mathrm{mg}) \mathrm{TEAB}$, were used for the synthesis of several clinically relevant PET tracers, including $\left[{ }^{18} \mathrm{~F}\right]$ fallypride [maximum radiochemical conversion $(\mathrm{RCC})=58 \%$ by HPLC $],\left[{ }^{18} \mathrm{~F}\right]$ fluoroethyltosylate $\left(94 \%\right.$ RCC) and $4-\left[{ }^{18} \mathrm{~F}\right]$ fluorobenzonitrile $(79 \%$ RCC). [Note that in the context of this discussion, RCC refers to labeling efficiency, typically determined by TLC or HPLC analysis of the crude reaction mixture, not isolated radiochemical yield (RCY) ${ }^{17}$. This distinction is necessary because in many cases the investigators did not isolate the product from the reaction mixture.] Another example is the work of Blecha, et al., who reported the quantitative elution of $\left[{ }^{18} \mathrm{~F}\right] \mathrm{F}^{-}$from a $12.6 \mathrm{mg} \mathrm{MP}-1$ cartridge (ORTG, Inc.) using 1-2 mL solutions of $\mathrm{K}_{2} \mathrm{CO}_{3} / \mathrm{K}_{2.2 .2}$ in $97 \% \mathrm{DMF}$ or $99 \% \mathrm{MeCN}^{18}$. Several aromatic and aliphatic substrates were successfully radiolabeled (e.g. 4- $\left[{ }^{18} \mathrm{~F}\right]$ fluorobenzonitrile from 4-nitrobenzonitrile, $50 \%$ RCC; from 4-trimethylammonium triflate benzonitrile, 95\% RCC) by mixing a fraction of the eluate (1/8 to $1 / 4$ of the total radioactivity) with a solution of the precursor in dry solvent. It's important to note that in both of these cases only a small fraction (10-25\%) of the total amount of the $\left[{ }^{18} \mathrm{~F}\right] \mathrm{F}^{-}$eluted from the AEX cartridge was used in each labeling reaction, which significantly reduces both the amount of base and the amount of water in the reaction mixture.

Kniess, et al. prepared $\left[{ }^{18} \mathrm{~F}\right]$ fluoroethyltosylate using $\left[{ }^{18} \mathrm{~F}\right] \mathrm{F}^{-}$in $\mathrm{K}_{2.2 .2}$. and $\mathrm{K}_{2} \mathrm{CO}_{3}, \mathrm{KOH}$, or $\mathrm{K}_{2} \mathrm{C}_{2} \mathrm{O}_{4}$ solu-

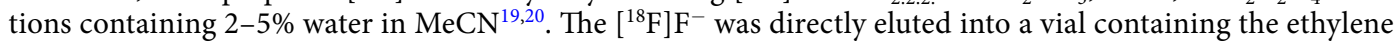
$\mathrm{di}\left(p\right.$-toluenesulfonate) precursor $(7 \mathrm{mg})$ and $\mathrm{Cs}_{2} \mathrm{CO}_{3}(6.5 \mathrm{mg})^{21}$ which was then heated $\left(100^{\circ} \mathrm{C}, 15 \mathrm{~min}\right)$ to produce $\left[{ }^{18} \mathrm{~F}\right]$ fluoroethyltosylate $(\mathrm{RCC}=76-96 \%)$. This synthesis used large amounts of a robust precursor $(7 \mathrm{mg})$ and carbonate $(50 \mu \mathrm{mol}$ total), so additional studies are probably warranted to establish the substrate scope. Most recently, Kwon et al. reported $86 \%\left[{ }^{18} \mathrm{~F}\right] \mathrm{F}^{-}$elution efficiency from $46 \mathrm{mg}$ QMA columns using a solution of $\mathrm{K}_{2.2 .2} /$ $\mathrm{K}_{2} \mathrm{CO}_{3}$ in $96 \mu \mathrm{L} \mathrm{H}_{2} \mathrm{O}$ in $\mathrm{MeCN}(600 \mu \mathrm{L}$ total volume) water/MeCN mixtures. The eluate was then diluted with a solution of the precursor (1-3 mg) in $1.4 \mathrm{~mL}$ DMSO or DMA, and the resulting reaction mixtures were heated $\left(140{ }^{\circ} \mathrm{C}, 10 \mathrm{~min}\right)$ to afford $\left[{ }^{18} \mathrm{~F}\right] \mathrm{PSS} 232,\left[{ }^{18} \mathrm{~F}\right] \mathrm{MISO}$ and $\left[{ }^{18} \mathrm{~F}\right]$ fallypride ${ }^{22}$. The RCCs ranged from $15-46 \%$ (measured by HPLC). Notably, they observed that the RCC of $\left[{ }^{18} \mathrm{~F}\right]$ fallypride prepared by manual synthesis (45\%) was similar to that obtained using an automated synthesizer (46\%), suggesting that a non-anhydrous approach at this scale might be amenable to the clinical production of ${ }^{18} \mathrm{~F}$ PET tracers. It's worth noting that the RCY of $\left[{ }^{18} \mathrm{~F}\right]$ fallypride was only $25 \%$, slightly more than half the RCC, highlighting the distinction between RCC and RCY and the fact that RCCs measured by HPLC often overestimate $\left[{ }^{18} \mathrm{~F}\right] \mathrm{F}^{-}$incorporation ${ }^{23}$. 


\begin{tabular}{|l|l|l|l|l|l|}
\hline Entry & $\begin{array}{l}\text { AEX } \\
\text { Reagent }\end{array}$ & $\begin{array}{l}\text { Elution } \\
\text { Volume }(\boldsymbol{\mu L})\end{array}$ & $\begin{array}{l}\text { Elution } \\
\text { Matrix }\end{array}$ & $\begin{array}{l}\text { \% Elution } \\
\text { Efficiency }( \pm \boldsymbol{\sigma})\end{array}$ & $\boldsymbol{n}=$ \\
\hline 1 & TEAB & 500 & $100 \% \mathrm{H}_{2} \mathrm{O}$ & $97(<1)$ & 3 \\
\hline 2 & TEAB & 500 & $90 \% \mathrm{MeCN}$ & $89(6)$ & 5 \\
\hline $3 *$ & TEAB & 500 & $90 \% \mathrm{MeCN}$ & $76(7)$ & 4 \\
\hline 4 & TEAB & 500 & $90 \% \mathrm{DMSO}$ & $59(4)$ & 3 \\
\hline 5 & TEAB & 100 & $50 \% \mathrm{MeCN}$ & $95(2)$ & 3 \\
\hline 6 & TEAB & 100 & $50 \% \mathrm{DMSO}$ & $92(3)$ & 5 \\
\hline 7 & TEAP & 100 & $50 \% \mathrm{MeCN}$ & $94(2)$ & 5 \\
\hline 8 & TEAP & 100 & $50 \% \mathrm{DMSO}$ & $94(4)$ & 10 \\
\hline 9 & TEATos & 100 & $50 \% \mathrm{MeCN}$ & $95(3)$ & 3 \\
\hline 10 & TEATos & 100 & $50 \% \mathrm{DMSO}$ & $95(1)$ & 2 \\
\hline 11 & TEAB & 100 & $70 \% \mathrm{MeCN}$ & $93(<1)$ & 4 \\
\hline 12 & TEAB & 100 & $70 \% \mathrm{DMSO}$ & $85(4)$ & 3 \\
\hline 13 & TEAP & 100 & $70 \% \mathrm{MeCN}$ & $90(6)$ & 6 \\
\hline 14 & TEAP & 100 & $70 \% \mathrm{DMSO}$ & $80(4)$ & 5 \\
\hline 15 & TEATos & 100 & $70 \% \mathrm{MeCN}$ & $95(2)$ & 14 \\
\hline $16 * *$ & TEATos & 100 & $70 \% \mathrm{MeCN}$ & $95(1)$ & 16 \\
\hline 17 & TEATos & 100 & $70 \% \mathrm{DMSO}$ & $89(5)$ & 3 \\
\hline & & & & & \\
\hline
\end{tabular}

Table 1. Efficiency of $\left[{ }^{18} \mathrm{~F}\right] \mathrm{F}^{-}$elution from MP-1 columns using tetraethylammonium salts in organic solvent-water mixtures. Mass of MP-1 resin was $10-12 \mathrm{mg}$. Elution efficiencies are DC. The mass of the tetraethylammonium salt was $7.8 \mu \mathrm{mol}$ unless noted otherwise. Owing to its explosive potential when dry, TEAP is typically sold 'damp' ( 10\% water), which hampers an accurate measurement of TEAP mass. $* \mathrm{TEAB}=3.9 \mu \mathrm{mol}$. $* * \mathrm{QMA}$ column used (carbonate form).

The following report describes an approach that, informed by these previous studies, facilitates the synthesis of ${ }^{18} \mathrm{~F}$-labeled PET tracers under non-anhydrous reaction conditions ( 3 or $5 \%$ water in $1 \mathrm{~mL}$ total solvent; Fig. $1 \mathrm{~b}$ ). In contrast to the approach of Brichard and Aigbirhio ${ }^{16}$, this approach uses the entire volume of $\left[{ }^{18} \mathrm{~F}\right] \mathrm{F}^{-}$eluted from the anion exchange. The reaction conditions thus reflect typical radiopharmaceutical production conditions. This work also introduces the use of minimally basic tetraethylammonium salts (vs. $\mathrm{HCO}_{3}{ }^{-}$or $\mathrm{CO}_{3}{ }^{2-}$ ) as $\left[{ }^{18} \mathrm{~F}\right]$ $\mathrm{F}^{-}$eluents with the expectation that the resulting $\left[{ }^{18} \mathrm{~F}\right] \mathrm{F}^{-}$solutions might prove more suitable for ${ }^{18} \mathrm{~F}$-labeling of base-sensitive precursors. Finally, we report a protocol for the synthesis of $\left[{ }^{18} \mathrm{~F}\right]$ fallypride as the proof-of-concept for this "non-anhydrous, minimally basic" (NAMB) approach.

\section{Results and Discussion}

Commercially available AEX columns containing 10-12 mg of standard QMA (capacity = $\sim 0.2 \mathrm{meq} / \mathrm{g}$ ) or MP-1 (capacity $=\sim 0.7 \mathrm{meq} / \mathrm{g}$ ) resin were used for $\left[{ }^{18} \mathrm{~F}\right] \mathrm{F}^{-}$trapping. These small columns were connected to disposable syringes via a Luer-lock/hose barb adapter (Supplementary Fig. S2). After the $\left[{ }^{18} \mathrm{~F}\right] \mathrm{F}^{-}$was trapped on the column, the column was washed with acetonitrile $(3 \mathrm{~mL})$ and argon was passed through the column for $10 \mathrm{~min}$ (Fig. 1b). The $\left[{ }^{18} \mathrm{~F}^{-} \mathrm{F}^{-}\right.$was then eluted with a tetraethylammonium salt in $100-500 \mu \mathrm{L}$ of MeCN or DMSO containing $10-50 \%$ water. We attempted to use lower water concentrations; however, at the lower water concentrations described by Brichard and Aigbirhio $\left(0-2 \% \mathrm{H}_{2} \mathrm{O}, 15 \mathrm{mg} / \mathrm{mL} \text { TEAB }\right)^{16}$, we observed that TEAB precipitated from the solution upon standing. Increasing the water content to $10-50 \%$ ensured that the salt remained in solution and facilitated $\left[{ }^{18} \mathrm{~F}\right] \mathrm{F}^{-}$extraction. After elution, a solution of the precursor in anhydrous solvent was added, reducing the final water concentration to $3-5 \%$ in a $1 \mathrm{~mL}$ reaction volume.

Table 1 summarizes the optimization of the parameters for $\left[{ }^{18} \mathrm{~F}\right] \mathrm{F}^{-}$elution from the MP-1 AEX columns. We first investigated TEAB $(7.8 \mu \mathrm{mol}, 1.5 \mathrm{mg})$ in $500 \mu \mathrm{L} 90 \% \mathrm{MeCN}$ or DMSO/10\% $\mathrm{H}_{2} \mathrm{O}$. In agreement with Brichard and Aigbirhio ${ }^{16}$, MeCN proved to be a superior eluent to DMSO. Decreasing the TEAB concentration by half $\left(3.9 \mu \mathrm{mol}\right.$ in $500 \mu \mathrm{L}$ of $\left.90 \% \mathrm{MeCN} / 10 \% \mathrm{H}_{2} \mathrm{O}\right)$ decreased the elution efficiency from $89 \%$ to $76 \%$ (entries 2 \& 3), and replacing MeCN with DMSO decreased the elution efficiency from 89\% to 59\% (Table 1, entries 2 \& 4). Considering that some ${ }^{18} \mathrm{~F}$ PET tracers suffer from low isolated yields due to the sensitivity of the precursor or product to heating in the presence of $\mathrm{HCO}_{3}{ }^{-}$or $\mathrm{CO}_{3}{ }^{2-}$, we also evaluated tetraethylammonium perchlorate (TEAP) and tetraethylammonium $p$-toluenesulfonate (TEATos) as minimally basic alternatives to TEAB. In this case, the only base present in the final "NAMB" reaction mixture was the small amount of carbonate present on the column after pre-conditioning by the manufacturer that is co-eluted with the $\left[{ }^{18} \mathrm{~F}\right] \mathrm{F}^{-}$.

Columns were reversed before elution of the $\left[{ }^{18} \mathrm{~F}\right] \mathrm{F}^{-}$. Elution in the same direction as $\left[{ }^{18} \mathrm{~F}\right] \mathrm{F}^{-}$capture resulted in lower elution efficiency $(<60 \%)$ in all cases, except when eluting a QMA column using $7.8 \mu$ mol AEX reagent in $50 \% \mathrm{MeCN} /$ water $(100 \mu \mathrm{L})$. Under these conditions, the elution efficiencies in the forward direction using TEAB, TEAP, and TEATos were 82,79 , and $98 \%$ respectively.

Entries 5-10 in Table 1 summarize the efficiency of $\left[{ }^{18} \mathrm{~F}\right] \mathrm{F}^{-}$elution using $7.8 \mu \mathrm{mol}$ of TEAB, TEAP or TEATos in $100 \mu \mathrm{L}$ of $50 \%$ organic solvent $/ 50 \%$ water. In these examples, the elution efficiency was higher (92-95\%) than with $500 \mu \mathrm{L}$ of $90 \%$ organic solvent/10\% water, despite the smaller elution volume. Furthermore, when the eluent contained 50\% (vs. 10\%) water, MeCN showed no advantage over DMSO. Although beneficial during elution 


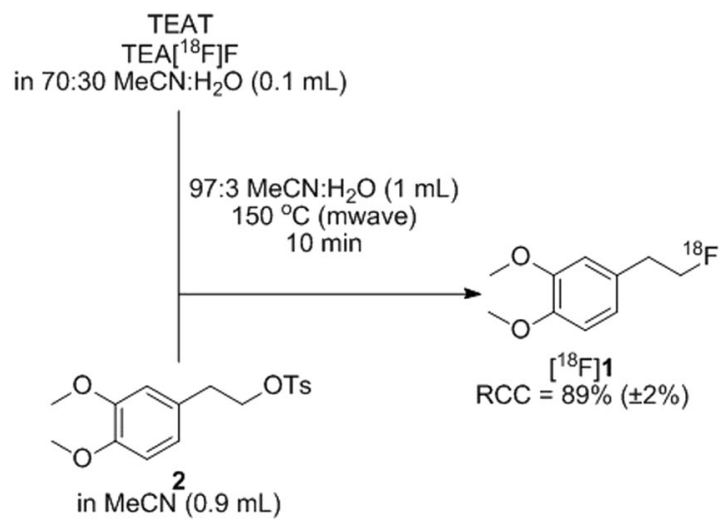

Figure 2. Example radiosynthesis of model compound $\left[{ }^{18} \mathrm{~F}\right] 1$ using the "NAMB" ${ }^{18} \mathrm{~F}$-fluorination method (Table 2, entry 11).

\begin{tabular}{|l|l|l|l|}
\hline Entry & AEX Reagent* & Solvent Matrix & $\begin{array}{l}\text { \% RCC of }\left[{ }^{18} \mathbf{F}\right] \mathbf{1} \text { by } \\
\text { TLC** }( \pm \sigma)\end{array}$ \\
\hline 1 & TEAB & $95 \% \mathrm{MeCN}$ & $\begin{array}{l}55(<1), 56(1), 59 \\
(<1)\end{array}$ \\
\hline 2 & TEAB & $95 \%$ DMSO & $\begin{array}{l}56(1), 62(<1), 69 \\
(<1)\end{array}$ \\
\hline 3 & TEAP & $95 \% \mathrm{MeCN}$ & $72(2)$ \\
\hline 4 & TEAP & $95 \%$ DMSO & $65(<1)$ \\
\hline 5 & TEATos & $95 \% \mathrm{MeCN}$ & $\begin{array}{l}53(1), 59(<1), 55 \\
(3), 51(<1)\end{array}$ \\
\hline 6 & TEATos & $95 \% \mathrm{DMSO}$ & $54(1)$ \\
\hline 7 & TEAB & $97 \% \mathrm{MeCN}$ & $88(1)$ \\
\hline 8 & TEAB & $97 \% \mathrm{DMSO}$ & $72(<1)$ \\
\hline 9 & TEAP & $97 \% \mathrm{MeCN}$ & $77(<1)$ \\
\hline 10 & TEAP & $97 \% \mathrm{DMSO}$ & $77(1)$ \\
\hline 11 & TEATos & $97 \% \mathrm{MeCN}$ & $89(2)$ \\
\hline 12 & TEATos & $97 \% \mathrm{DMSO}$ & $83(1)$ \\
\hline
\end{tabular}

Table 2. Reaction conditions evaluated for the ${ }^{18} \mathrm{~F}$-labeling of 2 . Reaction conditions: $4.5 \mu \mathrm{mol}(1.5 \mathrm{mg})$ of 2 in $1 \mathrm{~mL}, 150^{\circ} \mathrm{C}, 10 \mathrm{~min}$. $* 7.8 \mu \mathrm{mol}$. Owing to its explosive potential when dry, TEAP is typically sold "damp" ( $\sim 10 \%$ water), which hampers accurate weighing. **Silica gel chromatography with ethyl acetate as mobile phase. Each value is the average of three measurements and represents a unique radiosynthesis.

of $\left[{ }^{18} \mathrm{~F}\right] \mathrm{F}^{-}$from the column, the additional water may have a deleterious effect on subsequent ${ }^{18} \mathrm{~F}$-fluorination chemistry, so we also evaluated eluents containing $30 \%$ water (entries 11-17). Under these conditions, TEAP in $70 \% \mathrm{MeCN}$ (90\% elution efficiency) was slightly inferior to TEAB (94\% elution efficiency) and TEATos (94\% elution efficiency). As expected, $\left[{ }^{18} \mathrm{~F}\right] \mathrm{F}^{-}$elution efficiency was higher with $70 \% \mathrm{MeCN}$ than with $70 \% \mathrm{DMSO}$. When TEATos in $70 \% \mathrm{MeCN}$ was used as eluent, there was no apparent difference in elution efficiency between the QMA and MP-1 cartridges (both 95\% elution efficiency).

The ability of tetraethylammonium salts to facilitate nucleophilic ${ }^{18} \mathrm{~F}$-fluorinations in "damp" MeCN or DMSO was assessed using $\left[{ }^{18} \mathrm{~F}\right] \mathbf{1}$ as a model compound (Fig. 2). Cartridge eluates $(100 \mu \mathrm{L})$ containing $30 \%$ water $/ 70 \%$ organic solvent or $50 \%$ water $/ 50 \%$ organic solvent were diluted with a solution of precursor $2(1.5 \mathrm{mg})$ in anhydrous organic solvent $(900 \mu \mathrm{L})$ such that the final reaction volume was $1 \mathrm{~mL}$ and the final water content was $3 \%$ or $5 \%$. The reaction mixtures were then heated by microwave irradiation $\left(150^{\circ} \mathrm{C}, 10 \mathrm{~min}\right)$ and assayed by radio-TLC (Table 2). Little difference in RCC was observed when comparing the three AEX reagents or the two organic solvents. However, the RCC of reactions carried out in 97\% organic solvent (Table 2, entries 7-12) was generally higher (72-89\%) than those carried out in 95\% organic solvent (51-72\%; entries 1-6). The highest yield was observed using TEATos in 97\% MeCN (89\%, Fig. 2). See Supplementary Fig. S3 for an example radio-TLC trace of an $\left[{ }^{18} \mathrm{~F}\right] 1$ reaction mixture.

The crude $\left[{ }^{18} \mathrm{~F}\right] \mathbf{1}$ reaction mixtures were largely free of radiochemical byproducts as determined by analytical HPLC (Fig. 3a). Furthermore, as the degree of precursor decomposition has been utilized by others as a metric of overall ${ }^{18} \mathrm{~F}$-fluorination reaction "mildness", it is worth noting that in reaction mixtures using TEAP or TEATos in $97 \% \mathrm{MeCN}$, precursor 2 remained largely intact after heating.

As some previous reports describing non-anhydrous ${ }^{18} \mathrm{~F}$-fluorination reactions are limited in either the choice of leaving group (e.g. -OTs only) ${ }^{11}$ or the mechanism of ${ }^{18} \mathrm{~F}$ incorporation (e.g. $\mathrm{S}_{\mathrm{N}} \mathrm{Ar}$ reactions only $)^{5}$, we tested the utility of the "NAMB" approach for the radiosynthesis of the ${ }^{18} \mathrm{~F}$ prosthetic molecule $4-\left[{ }^{18} \mathrm{~F}\right]$ fluor-obenzaldehyde 

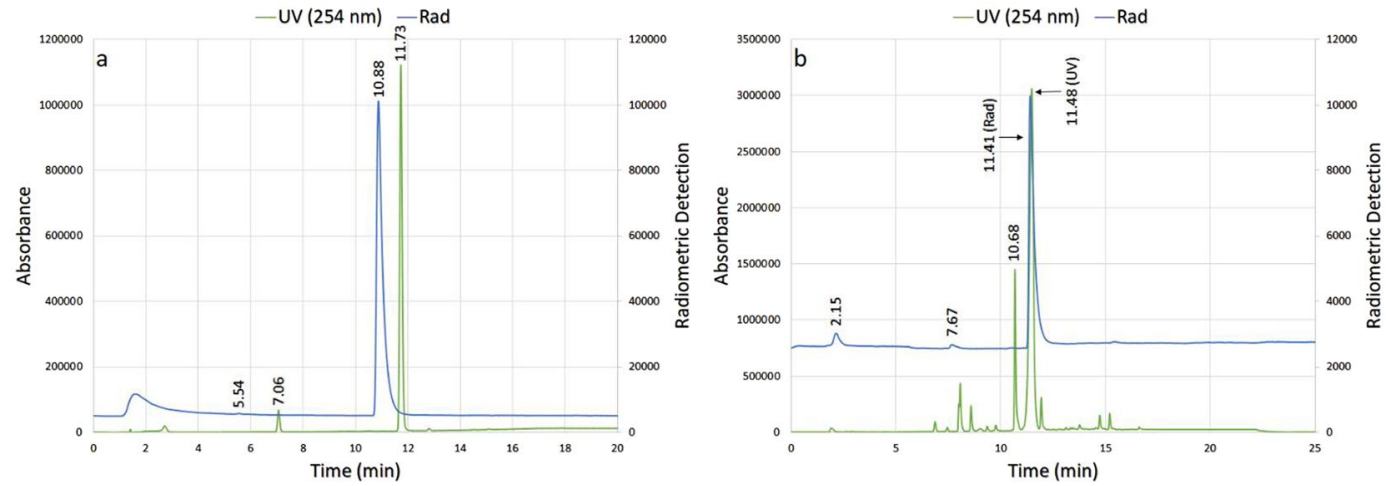

Figure 3. Analytical HPLCs of representative reaction mixtures of (a) model compound $\left[{ }^{18} \mathrm{~F}\right] 1$ and $(\mathrm{b})\left[{ }^{18} \mathrm{~F}\right]$ FBA using the "NAMB" strategy. Both traces were obtained using HPLC 1, Program A, as described in the Supplementary Information. (a) Reaction conditions: TEAP, $97 \% \mathrm{MeCN}, 150{ }^{\circ} \mathrm{C}, 10 \mathrm{~min} . \mathrm{t}_{\mathrm{R}}\left[{ }^{18} \mathrm{~F}\right] \mathbf{1}=10.88 \mathrm{~min}$. $\mathrm{t}_{\mathrm{R}}$ tosylated precursor $\mathbf{2}=11.73 \mathrm{~min}$. (b) Reaction conditions: TEAP, $97 \% \mathrm{DMSO}, 150^{\circ} \mathrm{C}, 10 \mathrm{~min} . \mathrm{t}_{\mathrm{R}}$ $\left[{ }^{18} \mathrm{~F}\right] \mathbf{3}=11.41 \mathrm{~min} ., \mathrm{t}_{\mathrm{R}} 4=11.48 \mathrm{~min}$.

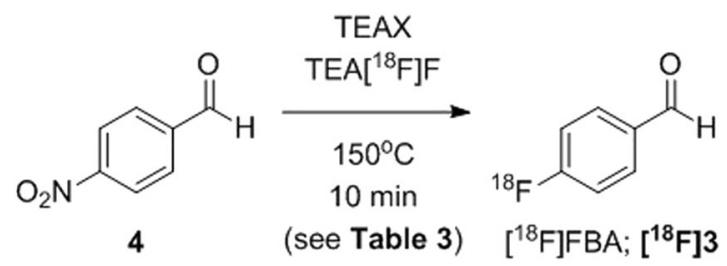

Figure 4. Radiosynthesis of $4-\left[{ }^{18} \mathrm{~F}\right]$ fluorobenzaldehyde $\left(\left[{ }^{18} \mathrm{~F}\right] 3\right)$ from 4-nitrobenzaldehyde (4). TEAX $=\mathrm{TEAB}$, TEAP or TEATos.

\begin{tabular}{|l|l|l|l|}
\hline Entry & AEX Reagent* & Solvent Matrix & $\begin{array}{l}\text { \% RCC of }\left[{ }^{18} \mathbf{F}\right] \text { FBA } \\
\text { by TLC } * * \boldsymbol{\sigma})\end{array}$ \\
\hline 1 & TEAB & $95 \% \mathrm{MeCN}$ & $0(<1)$ \\
\hline 2 & TEAP & $95 \% \mathrm{MeCN}$ & $0(<1)$ \\
\hline 3 & TEATos & $95 \% \mathrm{MeCN}$ & $1(<1)$ \\
\hline 4 & TEAB & $95 \%$ DMSO & $43(1)$ \\
\hline 5 & TEAP & $95 \%$ DMSO & $45(1)$ \\
\hline 6 & TEATos & $95 \%$ DMSO & $50(1)$ \\
\hline 7 & TEAB & $97 \%$ DMSO & $76(2)$ \\
\hline 8 & TEAP & $97 \%$ DMSO & $68(3)$ \\
\hline 9 & TEATos & $97 \%$ DMSO & $64(1)$ \\
\hline
\end{tabular}

Table 3. Summary of the reaction conditions evaluated for the synthesis of $\left[{ }^{18} \mathrm{~F}\right] \mathrm{FBA}$. Reaction conditions: 4-nitrobenzaldehyde $19.9 \mu \mathrm{mol}(3 \mathrm{mg})$ in $1 \mathrm{~mL}$. *7.8 $\mu \mathrm{mol}$. Owing to its explosive potential when dry, TEAP is typically sold "damp" ( 10\% water), which hampers an accurate measurement of TEAP mass. **Silica gel chromatography with ethyl acetate as mobile phase. Values represent an average of three measurements.

( $\left.\left[{ }^{18} \mathrm{~F}\right] \mathrm{FBA} ;\left[{ }^{18} \mathrm{~F}\right] 3\right)$ from 4-nitrobenzaldehyde (4; Fig. 4 and Table 3). Interestingly, this reaction proceeded in non-anhydrous solvent mixtures containing DMSO but not MeCN. As observed for model compound $\left[{ }^{18} \mathrm{~F}\right] \mathbf{1}$, a decrease in water content from $5 \%$ to $3 \%$ correlated with an increase in RCC from $43-50 \%$ (entries $4-6$ ) to $64-76 \%$ (entries $7-9$ ). See Fig. $3 b$ for a representative radio-HPLC trace of the $\left[{ }^{18} \mathrm{~F}\right] 3$ reaction mixture and Supplementary Fig. S4 for an example radio-TLC trace.

In light of the promising results with $\left[{ }^{18} \mathrm{~F}\right] 1$ and $\left[{ }^{18} \mathrm{~F}\right] 3$, we sought to utilize "NAMB" ${ }^{18} \mathrm{~F}$-fluorination chemistry for the preparation of an established ${ }^{18} \mathrm{~F}$-labeled radiopharmaceutical. This method was, therefore, applied to the synthesis of $\left[{ }^{18} \mathrm{~F}\right]$ fallypride $\left(\left[{ }^{18} \mathrm{~F}\right] 5 ;(S)-N\right.$ - $\left[(1\right.$-allyl-2-pyrrolidinyl)methyl $]-5-\left(3-\left[{ }^{18} \mathrm{~F}\right]\right.$ fluoropropyl)-2,3-dimethoxybenzamide), a clinically useful $\mathrm{D}_{2} / \mathrm{D}_{3}$ receptor antagonist ${ }^{24,25}$ (Fig. 5). The standard synthesis of $\left[{ }^{18} \mathrm{~F}\right]$ fallypride is known to be base-sensitive, because of the tendency of the tosyl-fallypride precursor 6 to undergo hydrolysis and elimination side reactions ${ }^{26}$, making this compound a good candidate with which to evaluate this minimally basic synthesis.

For these experiments, $\left[{ }^{18} \mathrm{~F}\right] \mathrm{F}^{-}$was eluted from MP- 1 columns using TEAP or TEATos $(7.8 \mu \mathrm{mol})$ in $70 \%$ $\mathrm{MeCN}(100 \mu \mathrm{L})$. The eluate was diluted with a solution of $6(1 \mathrm{mg})$ in dry $\mathrm{MeCN}(900 \mu \mathrm{L})$, and the reaction 


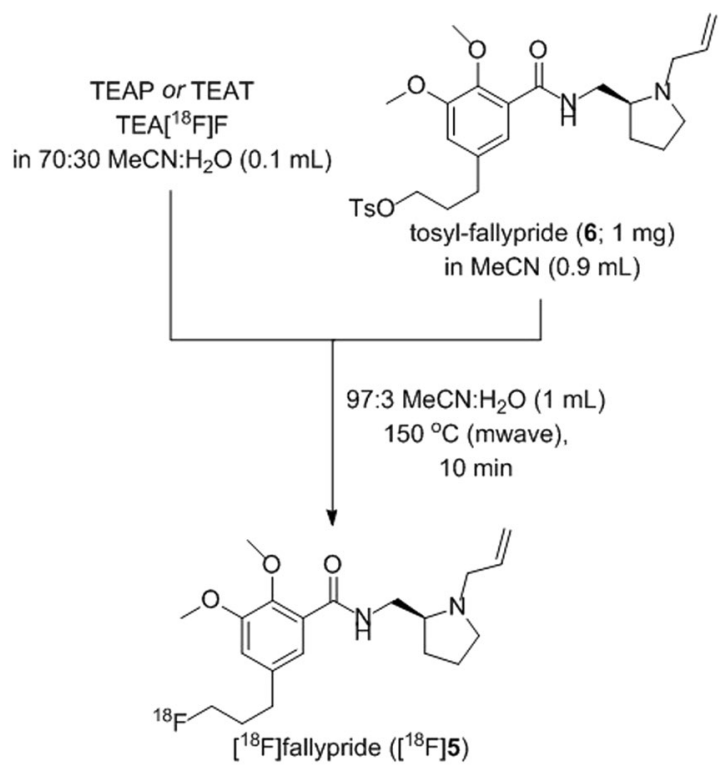

Figure 5. Tetraethylammonium salt-mediated radiosynthesis of $\left[{ }^{18} \mathrm{~F}\right]$ fallypride $\left(\left[{ }^{18} \mathrm{~F}\right] 5\right)$ under "NAMB" ${ }^{18} \mathrm{~F}$-fluorination conditions.

mixture was heated by microwave $\left(150^{\circ} \mathrm{C}, 10 \mathrm{~min}\right)$. See Supplementary Fig. S5 for an example radio-TLC trace. $\left[{ }^{18} \mathrm{~F}\right]$ Fallypride was isolated by semi-preparative HPLC followed by solid-phase extraction and formulation in $10 \% \mathrm{EtOH}$ in saline. Radiolabeling efficiencies (RCCs) of $\left[{ }^{18} \mathrm{~F}\right]$ fallypride were generally higher when TEAP was used $(64-81 \%, n=4)$ vs. TEATos $(55-72 \%, n=5)$, but this did not translate in a significant difference in the radio-chemical yield (vide infra). The amount of precursor used in this reaction ( $1 \mathrm{mg}$ ) was less than that used in other standard [i.e. $\mathrm{K}\left[{ }^{18} \mathrm{~F}\right] \mathrm{F}-\mathrm{K}_{2.2 .2} /(\text { bi)carbonate }]^{24,26-28}$ and non-standard ${ }^{4,10,11,22}$ syntheses of $\left[{ }^{18} \mathrm{~F}\right]$ fallypride $(2-40 \mathrm{mg})$. In contrast to most other $\left[{ }^{18} \mathrm{~F}\right]$ fallypride syntheses carried out without azeoptropic drying of the $\left[{ }^{18} \mathrm{~F}\right]$ $\mathrm{F}^{-4,10,11,16}$, this reaction was also carried out in a reaction volume $(1 \mathrm{~mL})$ that is compatible with typical automated radio-pharmaceutical production systems.

The importance of the interplay between the $\left[{ }^{18} \mathrm{~F}\right] \mathrm{F}^{-}$elution conditions and the $\left[{ }^{18} \mathrm{~F}\right] \mathrm{F}^{-}$labeling conditions is highlighted by the work of Lemaire et al. ${ }^{6}$, who showed that $\left[{ }^{18} \mathrm{~F}\right] \mathrm{F}^{-}$could be efficiently stripped from QMA resin with the phosphazine base $\mathrm{P}_{2} \mathrm{Et}$ in "damp" $\mathrm{MeCN}\left(0.63 \% \mathrm{H}_{2} \mathrm{O}\right)$. Subsequently, the entire eluate volume $(700 \mu \mathrm{L})$ was reacted with 6 in dry $\mathrm{MeCN}(0.5-1 \mathrm{~mL})$ containing 2-t-butyl-1,1,3,3-tetramethylguanidine without azeo-tropic drying of the $\left[{ }^{18} \mathrm{~F}\right] \mathrm{F}^{-}$. However, under these conditions, $20 \mathrm{mg}$ of $\mathbf{6}$ was required to achieve high RCC $(87 \%)$, presumably due to the larger final reaction volume $(>1 \mathrm{~mL})$ and the presence of a relatively large quantity of a very strong base $\left(\mathrm{P}_{2} \mathrm{Et} ; 45 \mu \mathrm{mol}\right)$ in the reaction mixture. Investigators were able to achieve an equally high product yield (86\%) using only $1 \mathrm{mg}$ of precursor, but this was only possible by employing a small fraction of the total eluate volume $\left(50 \mu \mathrm{L}\right.$ out of $900 \mu \mathrm{L}$, or $5.6 \%$ of the total radioactivity), which reduces the amount of $\mathrm{P}_{2} \mathrm{Et}$ present in the reaction mixture from $45 \mu \mathrm{mol}$ to $2.5 \mu \mathrm{mol}$. It is worth noting that $\mathrm{P}_{2} \mathrm{Et}$ does not itself displace the $\left[{ }^{18} \mathrm{~F}\right] \mathrm{F}^{-}$from the anion exchange resin. The $\left[{ }^{18} \mathrm{~F}\right] \mathrm{F}^{-}$is eluted by an anion, presumably $\mathrm{OH}^{-}$, produced in situ by $\mathrm{P}_{2}$ Et deprotonation of the water present in the eluent.

The HPLC profiles of $\left[{ }^{18} \mathrm{~F}\right]$ fallypride reaction mixtures employing TEAP and TEATos were very similar. In contrast to compound $\left[{ }^{18} \mathrm{~F}\right] \mathbf{1}$, significant decomposition of the starting material was observed after heating, with the major decomposition product found at 7.02 $\mathrm{min}$ in HPLC assays of the crude reaction mixtures (Fig. 6a). Nevertheless, only one small radioactive impurity was consistently observed (Fig. 6a, $\mathrm{t}_{\mathrm{R}}=8.20 \mathrm{~min}$ ). Isolated RCYs of $\left[{ }^{18} \mathrm{~F}\right] \mathbf{5}$ using TEAP in three separate experiments were 35,35 and $42 \%$. Using TEATos, the isolated RCYs in three separate experiments were 31, 32 and 37\%. Synthesis times ranged from 78-100 min from start-of-synthesis.

The yield of the NAMB $\left[{ }^{18} \mathrm{~F}\right]$ fallypride synthesis is approximately $40 \%$ higher than the $25 \%$ obtained by Kwon et al. in their non-anhydrous synthesis of $\left[{ }^{18} \mathrm{~F}\right]$ fallypride ${ }^{22}$. Comparing the yield of the NAMB synthesis to that obtained using standard anhydrous methods, Mukherjee, et al. reported yields of $35-42 \%$ in their original manual synthesis of $\left[{ }^{18} \mathrm{~F}\right]$ fallypride ${ }^{24}$, similar to the results obtained in this study. More recently, other investigators reported yields of 35-40\% for the automated synthesis of $\left[{ }^{18} \mathrm{~F}\right]$ fallypride ${ }^{29-31}$. The highest yield (68\%) was reported by Moon, et al. who used $10 \mu \mathrm{L}$ of a $40 \%$ solution of TBAB as the phase transfer catalyst and observed that the yield decreased to less than $50 \%$ in the presence of higher amounts of base ${ }^{26}$.

The radiochemical purity of all final products was $>99 \%$. Product identity was verified by co-injection of the ${ }^{18} \mathrm{~F}$-labeled compound with non-radioactive fallypride (Fig. 6b). Molar activities (MAs) were calculated based on a calibration curve prepared from $\left[{ }^{19} \mathrm{~F}\right] 5$. The MAs were similar regardless of PTC employed (TEAP: 5, 8 and $13 \mathrm{GBq} / \mu \mathrm{mol}$; TEATos: 4 and $7 \mathrm{GBq} / \mu \mathrm{mol})$. The moderate $\mathrm{MA}$ is attributable to our $\left[{ }^{18} \mathrm{~F}\right] \mathrm{F}^{-}$source $\left(\right.$i.e. $\left[{ }^{18} \mathrm{~F}\right]$ $\mathrm{F}^{-}$flushed from transfer lines after clinical production of other tracers) and to the relatively small amounts of 

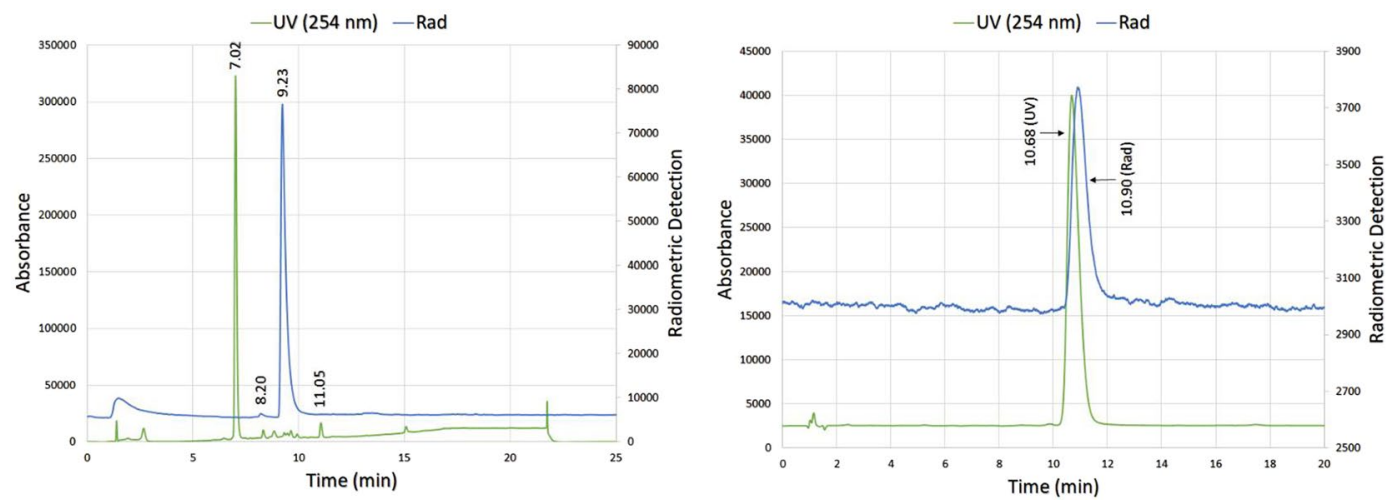

Figure 6. Analytical HPLCs of (a) $\left[{ }^{18} \mathrm{~F}\right]$ fallypride $\left(\left[{ }^{18} \mathrm{~F}\right] 5\right)$ reaction mixture and $(\mathrm{b})$ co-injection of $\left[{ }^{18} \mathrm{~F}\right] \mathbf{5}$ with non-radioactive standard. (a) HPLC conditions: HPLC 1, Program A, as described in the Supplementary Information. Reaction conditions: TEATos, $97 \% \mathrm{MeCN}, 150^{\circ} \mathrm{C}, 10 \mathrm{~min}$. $\left[{ }^{18} \mathrm{~F}\right] 5 \mathrm{t}_{\mathrm{R}}=9.23 \mathrm{~min}$. Precursor 6 $\mathrm{t}_{\mathrm{R}}=11.05$ min. (b) HPLC conditions: HPLC 1, Program C (See the Supplementary Information). UV- and $\gamma$-detectors were placed in serial, which results in slight differences in $t_{R} s$ between $\left[{ }^{18} \mathrm{~F}\right] \mathbf{5}\left(t_{R}=10.90 \mathrm{~min}\right)$ and $\left[{ }^{19} \mathrm{~F}\right] 5\left(\mathrm{t}_{\mathrm{R}}=10.68 \mathrm{~min}\right)$.

$\left[{ }^{18} \mathrm{~F}^{-} \mathrm{F}^{-}\right.$employed in the syntheses (74-370 MBq). Higher MAs can be achieved using larger quantities of freshly prepared $\left[{ }^{18} \mathrm{~F}\right] \mathrm{F}^{-}$.

Overall, for the synthesis of $\left[{ }^{18} \mathrm{~F}\right]$ fallypride under NAMB conditions, we did not observe a significant advantage of TEATos over TEAP in terms of ease of use (e.g. solubility), precursor tolerance (i.e. reaction "mildness"), radiochemical yield, or molar activity.

\section{Conclusions}

Solutions of tetraethylammonium tosylate and tetraethylammonium perchlorate in non-anhydrous solvent mixtures offer a straightforward means to efficiently extract $\left[{ }^{18} \mathrm{~F}\right] \mathrm{F}^{-}$from small AEX columns and facilitate the synthesis of ${ }^{18} \mathrm{~F}$-labeled aromatic and aliphatic compounds without the need for the azeotropic drying step that is ubiquitous in ${ }^{18} \mathrm{~F}-\mathrm{PET}$ chemistry. Since these anions do not contribute to the basicity of the reaction mixture, we describe this approach as "non-anhydrous, minimally basic" ("NAMB") ${ }^{18}$ F-fluorination chemistry. Tetraethylammonium tosylate offers a particularly attractive alternative to standard reagents because the tosylate anion is both non-basic and non-oxidizing and because it is already present in many nucleophilic ${ }^{18} \mathrm{~F}$-fluorination reactions as a leaving group.

As shown by the synthesis of $\left[{ }^{18} \mathrm{~F}\right]$ fallypride, "NAMB" labeling conditions can be used to prepare ${ }^{18} \mathrm{~F}-\mathrm{PET}$ tracers from commercially available, GMP-compliant precursor molecules and single portions of $\left[{ }^{18} \mathrm{~F}\right] \mathrm{F}^{-}$without the need to dry the $\left[{ }^{18} \mathrm{~F}\right] \mathrm{F}^{-}$prior to use. Furthermore, the "NAMB" method can accommodate volumes of aqueous $\left[{ }^{18} \mathrm{~F}\right] \mathrm{F}^{-}(1-2 \mathrm{~mL})$ and concentrations of precursor $(1-3 \mathrm{mg}$ in $1 \mathrm{~mL})$ that are commonly used in automated synthesis systems. Further improvements in this technique are anticipated as "NAMB" chemistry is evaluated for the synthesis of a wider variety of clinically relevant ${ }^{18} \mathrm{~F}$ radiopharmaceuticals.

\section{Experimental Section}

Example radiosynthesis of $\left[{ }^{18} \mathrm{~F}\right]$ fallypride. Preparation of active $\left[{ }^{18} \mathrm{~F}\right]$ fluoride. An aliquot of $\left[{ }^{18} \mathrm{~F}\right]$ $\mathrm{F}^{-}(90 \mathrm{MBq}, 2.44 \mathrm{mCi})$ in $\left[{ }^{18} \mathrm{O}\right] \mathrm{H}_{2} \mathrm{O}$ was diluted to $1.5 \mathrm{~mL}$ with $\mathrm{H}_{2} \mathrm{O}$ and the $\left[{ }^{18} \mathrm{~F}\right] \mathrm{F}^{-}$was trapped on an MP-1 anion-exchange column (MedChem Imaging, carbonate form, 10-12 mg), which was previously activated with $\mathrm{H}_{2} \mathrm{O}(1 \mathrm{~mL})$. After washing the column with anhydrous $\mathrm{MeCN}(3 \mathrm{~mL})$, Ar was passed through the column for $10 \mathrm{~min}$. Fluorine-18 was eluted from the column in the reverse direction into a microwavable test tube using a solution of tetraethylammonium tosylate (TEATos, $23.5 \mathrm{mg} / \mathrm{mL}, 100 \mu \mathrm{L}$ ) in 7:3 $\mathrm{MeCN}: \mathrm{H}_{2} \mathrm{O}$. Residual liquid was removed from the column using a syringe filled with air $(10 \mathrm{~mL})$.

${ }^{18}$ F-labeling reaction. Tosyl-fallypride $(6 ; 1 \mathrm{mg})$ in dry $\mathrm{MeCN}(900 \mu \mathrm{L})$ was added to the $\left[{ }^{18} \mathrm{~F}\right] \mathrm{F}^{-}$solution and the tube was crimp-sealed, magnetically stirred for $20 \mathrm{sec}$, and heated (microwave) to $150^{\circ} \mathrm{C}$ for $10 \mathrm{~min}$. After removing small aliquots for silica gel radio-TLC $\left(10 \% \mathrm{MeOH}\right.$ in $\left.\mathrm{CH}_{2} \mathrm{Cl}_{2}, 72 \pm 2 \% \mathrm{RCC}, n=4\right)$ and analytical HPLC (HPLC 1, Program A in the Supplementary Information), the reaction mixture was diluted with $0.1 \%$ TFA in water $(1 \mathrm{~mL})$ and injected onto a semi-preparative HPLC column (HPLC 2, Program B). The product was collected, diluted with water $(50 \mathrm{~mL})$, and trapped on a Sep-Pak ${ }^{\circledR} \mathrm{C}_{18}$ Light cartridge that was previously activated with $\mathrm{EtOH}(3 \mathrm{~mL})$ and water $(10 \mathrm{~mL})$. After washing the column with water $(5 \mathrm{~mL}),\left[{ }^{18} \mathrm{~F}\right]$ fallypride was eluted with $\mathrm{EtOH}(1 \mathrm{~mL})$ and diluted with $0.9 \%$ saline $(9 \mathrm{~mL})$. The final formulation was passed through a 0.2 micron filter to afford $22.1 \mathrm{MBq}(596 \mu \mathrm{Ci})$ of $\left[{ }^{18} \mathrm{~F}\right]$ fallypride (21\% non-decay corrected, $37 \%$ decay corrected). Product identity and molar activity were assessed by HPLC (HPLC 1, Program C). The synthesis time was $88 \mathrm{~min}$. from start-of-synthesis. 


\section{Data availability}

All data reported in this manuscript are available upon reasonable request by contacting the corresponding author.

Received: 24 December 2019; Accepted: 3 March 2020;

Published online: 22 April 2020

\section{References}

1. Schlyer, D. J., Bastos, M. A., Alexoff, D. \& Wolf, A. P. Separation of $\left[{ }^{18} \mathrm{~F}\right]$ fluoride from $\left[{ }^{18} \mathrm{O}\right]$ water using anion exchange resin. Int. J. Rad. Appl. Instrum. A 41, 531-533 (1990).

2. Hamacher, K., Coenen, H. \& Stocklin, G. Efficient stereospecific synthesis of no-carrier-added 2-[F-18]-fluoro-2-deoxy-d-glucose using aminopolyether supported nucleophilic-substitution. J. Nucl. Med. 27, 235-238 (1986).

3. Kilbourn, M. R. \& Huizenga, J. R. Fluorine-18 Labeling of Radiopharmaceuticals (National Academy Press, 1990).

4. Aerts, J. et al. Fast production of highly concentrated reactive F-18 fluoride for aliphatic and aromatic nucleophilic radiolabelling. Tetrahedron Lett. 51, 64-66 (2010).

5. Perrio, C. et al. $\left[{ }^{18} \mathrm{~F}\right]$-Fluoride capture and release: azeotropic drying free nucleophilic aromatic radiofluorination assisted by a phosphonium borane. Chem Comm. 53, 340-343 (2017).

6. Lemaire, C. E. et al. Fast Production of Highly Reactive No-Carrier-Added F-18 Fluoride for the Labeling of Radiopharmaceuticals. Angew. Chem. Int. Ed. Engl. 49, 3161-3164 (2010).

7. Mossine, A. V. et al. Development of Customized $\left[{ }^{18} \mathrm{~F}\right]$ Fluoride Elution Techniques for the Enhancement of Copper-Mediated LateStage Radiofluorination. Sci. Rep. 7, 233, https://doi.org/10.1038/s41598-017-00110-1 (2017).

8. Lee, S. J., Oh, S. J., Chi, D. Y., Moon, D. H. \& Ryu, J. S. High Yielding F-18 Fluorination Method by Fine Control of the Base. Bull. Korean Chem. Soc. 33, 2177-2180 (2012).

9. Seo, J. W., Lee, B. S., Lee, S. J., Oh, S. J. \& Chi, D. Y. Fast and Easy Drying Method for the Preparation of Activated F-18 Fluoride Using Polymer Cartridge. Bull. Korean Chem. Soc. 32, 71-76 (2011).

10. Wessmann, S. H., Henriksen, G. \& Wester, H. J. Cryptate mediated nucleophilic ${ }^{18} \mathrm{~F}$-fluorination without azeotropic drying. Nuklearmedizin 51, 1-8 (2012).

11. Sergeev, M. E., Morgia, F., Lazari, M., Wang, C. Jr. \& van Dam, R. M. Titania-catalyzed radiofluorination of tosylated precursors in highly aqueous medium. J. Am. Chem. Soc. 137, 5686-5694 (2015).

12. Richarz, R. et al. Neither azeotropic drying, nor base nor other additives: a minimalist approach to ${ }^{18} \mathrm{~F}$-labeling. Org. Biomol. Chem. 12, 8094-8099 (2014).

13. Neumann, C. N., Hooker, J. M. \& Ritter, T. Concerted nucleophilic aromatic substitution with ${ }^{19} \mathrm{~F}$ and ${ }^{18} \mathrm{~F}$. Nature. 534, 369-373 (2016).

14. Basuli, F., Zhang, X., Jagoda, E. M., Choyke, P. L. \& Swenson, R. E. Facile room temperature synthesis of fluorine-18 labeled fluoronicotinic acid-2,3,5,6-tetrafluorophenyl ester without azeotropic drying of fluorine-18. Nucl. Med. Biol. 43, 770-772 (2016).

15. Basuli, F. et al. Fast indirect fluorine-18 labeling of protein/peptide using the useful 6-fluoronicotinic acid-2,3,5,6-tetrafluorophenyl prosthetic group: A method comparable to direct fluorination. J. Label. Comp. Radiopharm. 60, 168-175 (2017).

16. Brichard, L. \& Aigbirhio, F. I. An Efficient Method for Enhancing the Reactivity and Flexibility of F-18 Fluoride Towards Nucleophilic Substitution Using Tetraethylammonium Bicarbonate. Eur. J. Org. Chem. 6145-6149 (2014).

17. Coenen, H. H. et al. Status of the 'consensus nomenclature rules in radiopharmaceutical sciences' initiative. Nucl. Med. Biol. 71, 19-22 (2019).

18. Blecha, J. E., Pun, M. \& VanBrocklin, H. F. Solvent exchange fluorination obviates F-18 fluoride ion resolubilization. J. Label. Comp. Radiopharm 54, S517 (2011).

19. Katsifis, A., Hamacher, K., Schnitter, J. \& Stöcklin, G. Optimization studies concerning the direct nucleophilic fluorination of butyrophenone neuroleptics. Appl. Radiat. Isot 44, 1015-1020 (1993).

20. Kniess, T., Laube, M. \& Steinbach, J. Hydrous ${ }^{18} \mathrm{~F}$-fluoroethylation - Leaving off the azeotropic drying. Appl. Radiat. Isot. 127, 260-268 (2017).

21. Cesium carbonate has been shown to facilitate certain nucleophilic ${ }^{18} \mathrm{~F}$-fluorination reactions. Coenen, H. H. D., Hamacher, K. D., Schüller, M., Stöcklin, G. P. D., Klatte, B. D. and Knöchel, A. P. D. Verfahren zur Herstellung von ${ }^{18} \mathrm{~F}$-markierten organischen Verbindungen durch nukleophilen Austausch, 1986. EP 0167103A2.

22. Kwon, Y. D., Son, J., Yun, M. J. \& Chun, J. H. Azeotropic drying-free aliphatic radiofluorination to produce PET radiotracers in a mixed organic solvent system. Tetrahedron Lett. 59, 2848-2852 (2018).

23. Ory, D. et al. Retention of $\left[{ }^{18} \mathrm{~F}\right]$ fluoride on reversed phase HPLC columns. J. Pharm. Biomed. Anal. 111, 209-214 (2015).

24. Mukherjee, J., Yang, Z. Y., Das, M. K. \& Brown, T. Fluorinated benzamide neuroleptics-III. Development of (S)-N-[(1-allyl-2pyrrolidinyl)methyl]-5-(3- $\left[{ }^{18} \mathrm{~F}\right]$ fluoropropyl)-2, 3-dimethoxybenzamide as an improved dopamine D-2 receptor tracer. Nucl. Med. Biol. 22, 283-296 (1995).

25. Buchsbaum, M. S. et al. D2/D3 dopamine receptor binding with [F-18]fallypride in thalamus and cortex of patients with schizophrenia. Schizophr. Res. 85, 232-244 (2006).

26. Moon, B. S. et al. Highly efficient production of $\left[{ }^{18} \mathrm{~F}\right]$ fallypride using small amounts of base concentration. Appl. Radiat. Isot. 68, 2279-2284 (2010).

27. Gao, M. et al. An improved synthesis of dopamine D2/D3 receptor radioligands $\left[{ }^{11} \mathrm{C}\right]$ fallypride and $\left[{ }^{18} \mathrm{~F}\right]$ fallypride. Appl. Radiat. Isot. 68, 1079-1086 (2010).

28. Brichard, L., Ferrari, V., Smith, R. \& Aigbirhio, F. I. Radiopharmaceuticals for Positron Emission Tomography in Radiochemical Syntheses, Vol. 1 (eds. Scott, P. J. H \& Hockley, B. G.) 95-102 (John Wiley \& Sons, 2012).

29. Mock, B. et al. Fully automated syntheses of ${ }^{11} \mathrm{C}$ fallypride and ${ }^{18} \mathrm{~F}$ fallypride. J. Label. Compd. Radiopharm. 52, S256-S320 (2009).

30. Lukic, D., Tamburella, C., Filannino, A., Lemoucheux, L. \& Seimbille, Y. Fully automated system for ${ }^{18} \mathrm{~F}$ fallypride routine production with the Tracerlab MX module. J. Label. Compd. Radiopharm 52, S315 (2009).

31. Kuhnast, B., Hinnen, F. \& Dolle, F. Production of ${ }^{18} \mathrm{~F}$ fallypride on a Tracerlab FX-FN synthesizer. J. Label. Compd. Radiopharm. 52 (2009).

\section{Acknowledgements}

The authors gratefully acknowledge financial support from the Branfman Family Foundation, the Children's Hospital Radiology Foundation, and the National Institute of Health (1R21-MH103718, 5R01-HL108107).

\section{Author contributions}

J.A.H.I. and A.B.P. conceived the experiments. J.A.H.I. and V.A. carried out the radioactive studies. J.A.H.I., A.W.S., Y.C. and J.L.N. carried out the non-radioactive syntheses. J.A.H.I. and A.B.P. wrote the manuscript. 


\section{Competing interests}

The authors declare no competing interests.

\section{Additional information}

Supplementary information is available for this paper at https://doi.org/10.1038/s41598-020-61845-y.

Correspondence and requests for materials should be addressed to A.B.P.

Reprints and permissions information is available at www.nature.com/reprints.

Publisher's note Springer Nature remains neutral with regard to jurisdictional claims in published maps and institutional affiliations.

(c) (i) Open Access This article is licensed under a Creative Commons Attribution 4.0 International License, which permits use, sharing, adaptation, distribution and reproduction in any medium or format, as long as you give appropriate credit to the original author(s) and the source, provide a link to the Creative Commons license, and indicate if changes were made. The images or other third party material in this article are included in the article's Creative Commons license, unless indicated otherwise in a credit line to the material. If material is not included in the article's Creative Commons license and your intended use is not permitted by statutory regulation or exceeds the permitted use, you will need to obtain permission directly from the copyright holder. To view a copy of this license, visit http://creativecommons.org/licenses/by/4.0/.

(C) The Author(s) 2020 